\title{
Antonio Machado: La experiencia como tensión poietica. Entre una arqueología y una teleología del sentido
}

\author{
Zenón Depaz Toledo \\ Universidad Nacional Mayor de San Marcos \\ chaclaqayllu@gmail.com
}

\begin{abstract}
Resumen
El hombre no tiene una naturaleza dada, por ello está permanentemente en trance de tener que hacerse a sí mismo. Ese camino es también un proceso de autoconocimiento. La historia del pensamiento muestra dos vías del autoconocimiento o autorrealización: una regresiva (arqueológica) y otra prospectiva (teleológica). Tomando como referente la poética de Antonio Machado, en este artículo sostenemos que ambas vías son convergentes y nos confrontan, al fin y al cabo, con un proceso inacabable de búsqueda y afirmación de la autonomía y, por tanto, de la libertad.
\end{abstract}

Palabras claves: Antonio Machado, poesía, experiencia, libertad.

\begin{abstract}
Man hasn't a given nature, that's why he is permanently having to make himself, task that amounts to selfknowledge. The history of thinking shows two ways to pursuit selfknowledge or selfrealization: one of them backward (archeological) and the other prospective (teleological). With Antonio Machado's poetics as background, in this article we defend that both ways are convergent and faces us, at last, with an endless process of searching and building of autonomy and freedom.
\end{abstract}

Keywords: Antonio Machado, Poetry, Experience, Freedom.

Recibido: 2/7/14 Aceptado: 10/9/14 Publicado on line: 10/2/15 
En relación a la fuente de la poiesis, entendida como creación de sentidos y significaciones, Antonio Machado hace decir a su heterónimo Juan de Mairena lo siguiente: "¿Cantaría el poeta sin la angustia del tiempo, sin esa fatalidad de que las cosas no sean para nosotros, como para Dios, todas a la par, sino dispuestas en serie?" Contrapone así el carácter inevitablemente fragmentario y perspectivista de la experiencia humana, a esa otra paradojal visión total que correspondería a lo que en la filosofía contemporánea se ha venido a denominar el ojo de Dios.

La radical contingencia humana aparece como un tema constante, casi obsesivo, en la poesía de Machado, así por ejemplo cuando dice: "Bajo los ojos del puente pasaba el agua sombría./ (Yo pensaba: iel alma mía!)/ Y me detuve un momento, / en la tarde, a meditar.../ ¿Qué es esta gota en el viento/ que grita al mar: soy el mar?" La angustia ante la radical contingencia de la temporalidad hace que conciba la poesía como escucha de la Verdad, o más bien de sus ecos, que sostienen esa nada que, a su juicio, es el mundo. Así, dice: "Tal vez la mano, en sueños,/ del sembrador de estrellas,/ hizo sonar la música olvidada/ como una nota de la lira inmensa,/ y la ola humilde a nuestros labios vino/ de unas pocas palabras verdaderas" 2 , con ello da curso a la antigua intuición pitagórica según la cual el cosmos, ámbito con orden y sentido, que concebimos como antípoda del caos, discurriría como una armonía musical, siendo por lo mismo esencialmente evanescente, aunque, paradójicamente, manifieste un orden matemático.

"El alma del poeta/ se orienta hacia el misterio", dice Machado, y añade que "sólo el poeta/ puede mirar lo que está lejos/ dentro del alma, en turbio/ y mago sol envuelto" . Había dicho también que toda poesía contiene una metafísica, es decir, la poesía -y el arte en general-, tanto como la filosofía y la religión darían cauce a la experiencia metafísica, consustancial al hombre. Más aún, hace decir a Juan de Mairena: "Los grandes poetas son metafísicos fracasados. Los grandes filósofos son poetas que creen en la realidad de sus poemas".

¿Y qué es aquello que estando dentro del alma y siendo a la vez el alma del mundo, el poeta y el filósofo sólo pueden mirar de lejos o, como dice también Machado, mirar sin ver? "iOjos que a la luz se abrieron/ un día para, después, / ciegos tornar a la tierra,/ hartos de mirar sin ver!"5 había dicho. También lo siguiente: "No, mi corazón no duerme./ Está despierto, despierto./ (...) mira (...)/ señas lejanas y escucha/ a orillas del gran silencio"6. Paradójicamente, de ese gran silencio es de dónde brotarían las señas más lejanas, las señales originarias, la significación primigenia, por tanto, el lenguaje. Aunque precisamente por ello, el lenguaje

1 Soledades, galerías y otros poemas, XIII.

2 Idem, LXXXVIII.

3 Idem, LXI

4 Idem.

5 Proverbios y cantares, XII.

6 Soledades, galerías y otros poemas, LX. 
experimenta allí su límite. Se trataría de aquello que el primer Wittgenstein, contemporáneo de Machado, denominó lo inefable, lo místico, aquello de lo cual no se puede hablar sino de modo oblicuo, aunque lo mejor que cabe hacer es corresponder con el silencio. De ese gran silencio -ese Gran Cero, como lo denomina también en otro poema- surge la trama matemática del cosmos, su orden y significación. Ante ello experimentamos el misterio, y éste se nos manifiesta dual. Al respecto dice: "Saber, nada sabemos,/ de arcano mar vinimos, a ignota mar iremos.../ Y entre los dos misterios está el enigma grave." ${ }^{7} \mathrm{Me}$ permitiré ensayar una conjetura con respecto a esa misteriosa unidad dúplice o duplicidad unitaria, intuición que atraviesa y sustenta la poética de Machado.

Dos adagios fundamentales, de origen oracular, resumen la vía hacia la sabiduría, propuesta en la antigüiedad griega. La primera, dice: "Conócete a ti mismo". Otra, de sentido convergente, aconseja: "Sé lo que eres". A través del tiempo, ambas hablan de la experiencia del sí mismo como una constante búsqueda y, por tanto, de su constitución como resultante de un activo proceso de reconocimiento y afirmación que no tendría final, como parece haber asumido Heráclito al decir: "Ni siquiera recorriendo todos los caminos hallarás los límites del alma; tan profundo es su logos" ¿. ¿De qué naturaleza es ese logos elusivo que, no obstante exceder todo sentido, constituye al sí mismo, sosteniéndolo como proceso permanente de reconocimiento y afirmación de sentido?

Los adagios antes citados parecen suponer que la experiencia de sí no nos es dada ni plenamente, ni como una condición inmediata. Más aún, la conciencia inmediata de sí bien podría ser una falsa conciencia y, en todo caso, nunca podría ser exhaustiva, es decir, "clara y distinta", como creyó Descartes, quien por ello hizo de la autoconciencia el soporte de la experiencia moderna del mundo, convirtiendo a éste en objeto, en cuanto lo supone radicalmente otro con relación al sujeto.

Para situar la poética de Antonio Machado en relación a este tema, traeré a colación dos otras aproximaciones al mismo tema, que conducen a pensar los límites de la modernidad y la tradición logocéntrica a que da culminación, y parecen buscar realizar también por una doble vía, quizás en última instancia convergente, el viejo propósito del conocimiento y la afirmación de sí mismo, presente en el antiguo modo de entender la sabiduría. Se trata del teleologismo hegeliano del sentido y la conciencia, y de esa suerte de arqueología del sentido que constituye el psicoanálisis freudiano.

Según Freud, el objetivo del psicoanálisis, como vía de reconocimiento y afirmación de sí mismo, podía resumirse en que "allí donde estaba el Ello

7 Proverbios y cantares, $\mathrm{XV}$.

8 Diógenes Laercio, Vidas de los filósofos, IX, 7

LETRAS 85 (122), 2014 
debo devenir Yo". De ese modo, nos remite a la sospecha, compartida por perspectivas como las de Marx o Nietzsche, de que la conciencia inmediata bien pudiera constituir una forma de engaño, al no ser propia, sino ajena o enajenada. Ello supone, a su vez, no sólo la distinción entre certeza y verdad, sino que la certeza inmediata de la conciencia nunca es tal, ya que se halla profundamente mediada por una experiencia de raíces inabarcables (como el logos heracliteano), en que el olvido es, inevitablemente, la otra cara de la memoria, y un horizonte siempre difuso enmarca y sostiene el ámbito más o menos claro de nuestra experiencia. Por su parte, a propósito de la tesis bergsoniana de que hay datos inmediatos en la conciencia, Machado dirá: "Enrique Bergson: Los datos/ inmediatos/de la conciencia. ¿Esto es/ otro embeleco francés?/ Este Bergson es un tuno"'. Lo que se sigue de ello, según Freud, es que el autoconocimiento, es decir, la autoconciencia, es paciente reconocimiento. La conciencia no está dada, hay que buscarla, construirla y re-construirla. El Yo surge y se afirma, en tanto instancia de decisión, desplazando al Ello impersonal, pulsional, que cubre de inicio el espacio que reclama la conciencia, haciéndose pasar por ella. Igualmente, Machado, refiriéndose al juego de roles que es la existencia humana, dirá que "la escena acaba/ con un dogma de teatro:/ En el principio era la máscara." 10

La búsqueda de afirmación del Yo, es decir, de la conciencia, como autoconciencia, equivale a la búsqueda y afirmación de la autonomía. Frente al ciego imperio del inconsciente pulsional, la búsqueda de sí mismo, con su exigencia de autoconocimiento y autorrealización, constituye una autopoiesis, condición fundamental de la autonomía pues, como diría Lacan, "el inconsciente es el discurso del Otro". En el inconsciente -donde en rigor, desaparecen las distinciones, incluyendo aquella que fija límites entre lo individual y lo colectivo- gobierna el principio del placer, como fuente de deseos, exigencias y significaciones de sesgo autista; por tanto, no es el lugar en que se afirma la persona, sino el de lo impersonal; de allí que el autismo que lo caracteriza no remite al sí mismo, sino al Ello; por lo que debemos buscar que éste ceda espacio a la afirmación consciente de la personalidad autónoma. Pero, ¿hasta qué punto es posible la autoconciencia? Ya el antiguo adagio heracliteano, antes citado, parece señalar que se sostendría en una tarea siempre renovada, inconclusa, que en el límite hallaría siempre un exceso de sentido, como inasible horizonte de nuestro "mundo".

La indicación freudiana según la cual "allí donde estaba el Ello debo devenir Yo", parte de la suposición de un originario imperio del Ello. Más aún, parece asumir que aquel imperativo de autoconciencia, no es plenamente

9 Campos de Castilla, CXXVIII.

10 Nuevas canciones XLVII. 
realizable, porque, en última instancia, se sostendría como impulso en el reino inextinguible del deseo. Por eso, Freud afirma que el deseo es indestructible. Lo sería por irrealizable. Por cierto, cabría preguntar qué es lo irrealizable en el deseo, puesto que al parecer este puede hallar satisfacción aun cuando fuera por vía de su sublimación en la fantasía. En la sorprendente sexta parte de $L a$ interpretación de los sueños, da una notable indicación al respecto. Allí remite a un poderoso y al parecer omnipresente deseo que no podría ser satisfecho, por cuanto su objeto es inimaginable: el de reintegración a un estado de absoluta indeterminación (de Totalidad, como diría Hegel), semejante al ớrદıрov del que hablase veintiséis siglos atrás Anaximandro; esto es, lo indeterminado, lo in-forme, que no obstante contendría, produciría y devoraría todas las formas, todo lo determinado que constituye el cosmos. Freud se refiere con ello al autismo originario, donde no hay Yo, un estado que es por tanto diferente al narcisismo -que más bien supone un Yo sobredimensionado-, situado en la génesis de la psique.

Describiendo la topología del sueño mediante el símil de un remolino, dice Freud que "todo sueño tiene por lo menos un lugar en el que es insondable, como un ombligo por el cual está unido al inconsciente"; haciendo notar con ello que el carácter textual del sueño es más visible en la cercanía al borde externo del remolino que en la zona más densa de su vórtice. Como en un remolino, donde las cosas que giran en el borde pueden distinguirse en su particularidad, la misma que desaparece en el vértigo del centro por donde se esfuma raudo todo lo que asoma, así también los sueños son más fácilmente interpretables cuanto más periférica su memoria. Al acercarnos al centro, todo orden tendería a desaparecer. De hecho, aún en la zona visible tiende a ser así; el principio de identidad, soporte fundamental de toda determinación, cede a simbolismos donde reinan la metáfora y el desplazamiento de sentido. Más aún, en el sueño una cosa suele ser varias, es y no es, como anunciando el estallido de toda determinación en la zona por donde el remolino conduce al inconsciente, que de ese modo se anuncia como una suerte de magma de significaciones, sin orden ni límite alguno, pero con potencialidad de producir todos los órdenes

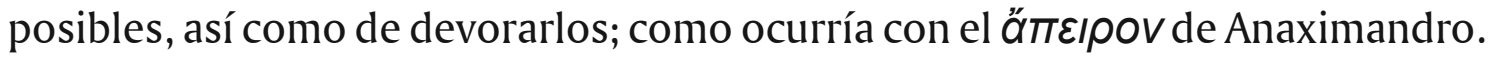

De ese modo, el inconsciente ignora el tiempo, como sucesión ordenada, y la contradicción. Sin orden ni distinción alguna, se trataría de un no-lugar, con lo que, dicho sea de paso, la tópica freudiana de la psique vendría a ser una curiosa tópica, al incorporar como un referente básico aquel no-lugar. Ese nolugar, reino pleno del principio del placer, antípoda del principio de realidad, contendría como antesala y fuente del deseo, como matriz y prototipo del sentido, de todo sentido y significación, una inconcebible "representación" originaria de todo -o del Todo- como sí mismo, en la que, por tanto, nada 
falta. Los sueños y los mitos -que son sueños colectivos- lo dejarían entrever en su horizonte o vórtice.

El deseo de Totalidad, de eternidad, de retorno a la plenitud del autismo originario, sería el deseo inextinguible que, en cuanto tal, sostendría la cultura y sus mayores realizaciones, como la religión, el arte, la filosofía o la ciencia, intentos inviables de reapropiación del todo, pero válidos como soportes de esperanza. De ese todo arquetípico en que echan raíces nuestros sueños parece hablar Machado cuando dice: "Yo escucho los cantos/ de viejas cadencias,/ que los niños cantan/ cuando en coro juegan, / y vierten en coro/ sus almas que sueñan,/ cual vierten sus aguas/ las fuentes de piedra:/ con monotonías/ de risas eternas, / que no son alegres,/ con lágrimas viejas, / que no son amargas/ (...) Cantaban los niños/ canciones ingenuas,/ de un algo que pasa/ y que nunca llega." 11

En el cantar 28 de sus Proverbios y Cantares, previo a aquel otro, famoso, en que equipara la vida con un camino que hacemos al andar, y a este nuestro camino con fugaces, inestables estelas en la mar, nuestro poeta ensaya la siguiente conjetura:

"Todo hombre tiene dos

batallas que pelear:

en sueños lucha con Dios;

y despierto con el mar."

Aquí destaca el carácter agónico de la vida, como una batalla, un permanente quehacer de incierto desenlace, en que nos vamos haciendo. Me permito una interpretación de los dos últimos versos que dan cuenta de las dos batallas en que nos jugamos nuestro destino: Sus metafóricos escenarios, igualmente móviles y matriciales, son los sueños y el mar.

Los sueños, puente regresivo hacia el inconsciente, contienen un simbolismo igualmente regresivo, arquetípico, y como tal, pasible de una suerte de arqueología del sentido que, de acuerdo a nuestra lectura de Freud, conduciría al agujero negro del autismo originario, una suerte de ópxń (como dirían los primeros filósofos griegos en busca de la fuentes del cosmos) o principio de

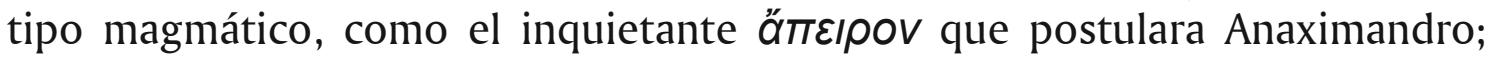
quizás Dios, entendido como totalidad impensable, como aspiración a la Unidad. En otro poema, dice también: "Anoche cuando dormía/ soñé, ibendita ilusión!,/ que era Dios lo que tenía/ dentro de mi corazón."12

En cuanto a la otra batalla, con el mar, en la vigilia, cabe recordar que ya en el viejo Heráclito, la metáfora de la vigilia aludía a la consciencia, a la lucidez buscada. "Al dormir nos sumergimos en un mundo propio, particular; pero

11 Soledades, galerías y otros poemas, VIII.

12 Idem, LIX. 
en vigilia habitamos un mundo común", habría sentenciado este filósofo ${ }^{13}$, al parecer aludiendo con ello al logos del que hablaba (señalando que llenaba el mundo entero y lo sostenía), término que suele traducirse preferentemente por "razón", cuando no se puede insistir en que es más que eso, pues significa también sentido, discurso (como discurrir) y, por tanto, aquello que constituye la palabra y sus posibilidades de significación y comunicación. En todo caso, la vigilia grafica la aspiración a la lucidez y a un mundo común de significaciones discursivamente sustentables y, por tanto, con aspiración a la validez universal que sostiene todo proyecto de convivencia no coercitivo, autónomo. El último verso del cantar de Machado nos recuerda, sin embargo, algo que no cabe olvidar para ratificarnos de continuo en ese proyecto de vida y cuidar sus condiciones de posibilidad: que el ámbito de su realización es precario como la superficie del mar, masa igualmente matricial, móvil, de inestables formas, soporte de caminos -o estelas- precarios, de caminos que comunican islas, rompiendo su aislamiento.

Considero que a diferencia del primer escenario metafórico -el de los sueños-, que es de carácter raigal, arquetípico y regresivo -y como tal terreno de una arqueología radical del sentido-, el mar, que es el otro ámbito metafórico en que, según Machado, discurre nuestro destino, siendo un espacio vinculado en nuestro imaginario a la aventura, es más bien de orientación teleológica, de apertura hacia el futuro, de realización de formas, vías y estados inéditos, donde la búsqueda del sentido sería más bien ascendente. Mientras la arqueología del sentido, que hurga en el inconsciente, deberá reconocer en él la fuente de claves de significación de naturaleza arquetípica, tendientes a la repetición y, por lo mismo, a subsumir toda afirmación de lo nuevo -con lo cual el inconsciente constituiría un factor de repetición y aún de regresión que nos mantiene cautivos de la infancia y de fases aún más tempranas-, una teleología del sentido, como la que sugieren las metáforas de la vigilia y de las estelas en la mar, supondría una estrategia de búsqueda del sentido en que la cultura, la creatividad y la novedad, abren un terreno propicio para la conciencia como autopoiesis.

No obstante, en esta perspectiva toman cuerpo nociones con pretensiones de cierre del discurso y la experiencia, tales como la noción hegeliana de Conciencia Absoluta, postulada como el resultado final, igualmente inconcebible, de la conciencia finita, histórica. Lo pertinente es no perder de vista su condición de límite inaprehensible y, por lo mismo, incapaz de proveer certezas que nos eximan de la responsabilidad de construir por cuenta propia el ámbito de nuestra convivencia. Machado, que lo sabe, que entiende el carácter conjetural, provisional, de nuestras certezas, dice: "así voy yo,/ (...)

13 Citado por Plutarco, De superst., 3

LETRAS 85 (122), 2014 
pobre hombre en sueños,/ siempre buscando a Dios entre la niebla"14. Ese Dios, gran cero, gran silencio, "el Ser que se es" -como lo invoca también en otro poema ${ }^{15}$-, es, en su lejanía, nuestro anclaje en la nada. A ese inconcebible Dios, a esa totalidad que es nuestro impulso, nuestro ápXń y nuestro TÉ^os, principio y fin, alfa y omega, está dirigida la poesía de Machado. Como él dijera: "Al Dios de la distancia y de la ausencia,/ del áncora en el mar, la plena mar.../Él nos libra del mundo-omnipresencia-,/ nos abre senda para caminar./ Con la copa de sombra bien colmada,/ con este nunca lleno corazón,/ honremos al Señor que hizo la Nada/ y ha esculpido en la fe nuestra razón."16

\section{Consideraciones finales}

Desde antiguo, la búsqueda de sí mismo fue entendida como un proceso de autoconstitución, por lo demás sin término visible. Ello supone que la experiencia de sí no es inmediata y que la autoconciencia suele ser una falsa conciencia. Tras el fracaso de la pretensión de autofundamentación de la conciencia en la filosofía cartesiana, la formación de la autoconciencia (o la constitución del sujeto) fue explorada en dos direcciones básicas, aparentemente opuestas, pero en realidad convergentes (por cuanto ambas remiten al encuentro de la totalidad): por una parte, el teleologismo hegeliano, para el cual la autoconciencia genuina, que se produce como saber absoluto, equivale al encuentro de sí mismo en la totalidad del Espíritu (es decir, en la totalidad de lo real, entendido como objetivación del espíritu) y se produce como coronación de la experiencia intersubjetiva; por otra parte, la arqueología del saber propiciada por Freud (también por Nietzsche o Foucault), busca la fuente del sentido -y, por tanto, el soporte de la subjetividad- por vía regresiva. La poesía y el arte en general -que, al igual que la filosofía y la religión, también dan curso a la dimensión metafísica de la experiencia humana- han ensayado igualmente aproximaciones a este tema desde el ámbito simbólico; tal es el caso de la poética de Antonio Machado, donde también se asume que desde nuestra radical contingencia e historicidad que se configura por referencia a un antes y un después (un arjé y un telos) nos afirmamos en un mundo común, construyendo nuestra libertad de cara al destino insondable.

\section{Referencias bibliográficas}

DESCARTES, R. (2003) Discurso del método. Madrid: Tecnos.

ÉLUARD, Paul (2013) El Amor la Poesía. Madrid: Visor.

14 Soledades, galerías y otros poemas, LXXVIII.

15 De un cancionero apócrifo, CLXVII, XV.

16 Idem, CLXX. 
FOUCAULT, Michel (1974) Las palabras y las cosas: una arqueología de las ciencias humanas. México: Siglo XXI.

FOUCAULT, Michel (1996) Tecnologías del yo. Barcelona: Paidós.

FREUD, Sigmund (2000) La interpretación de los sueños. Madrid: Editorial Biblioteca Nueva.

GADAMER, Hans Georg (1997) Historia y hermenéutica. Barcelona: Paidós.

HEGEL, G.W.F. (1996) Fenomenología del espíritu. México: Fondo de Cultura Económica.

HEIDEGGER, Martin (1972) Ser y tiempo. México: Fondo de Cultura Económica.

HEIDEGGER, Martin (1996) Caminos de bosque. Madrid: Alianza Editorial.

MACHADO, Antonio (1999) Poesías completas. Madrid: Espasa.

MARX, Karl (1972) La ideología alemana. Montevideo: Pueblos unidos.

RICOEUR, Paul (2003) El conflicto de las interpretaciones. México: FCE.

RICOEUR, Paul (1996) Sí mismo como otro. Madrid: Siglo XXI.

RUSSO DELGADO, José Antonio (1963) El hombre y la pregunta por el ser. Lima: Universidad Nacional Mayor de San Marcos. 
